\title{
Determinants of Low Birth Weight Among Newborn Delivered At Public Hospital in Silte Zone, Southern Ethiopia: Case Control Study
}

Mubarek Hussen Mohammed

Worabe comprehensive specalized hospital

Yasin Awol Wabe ( $\square$ awolyasin30@gmail.com )

Worabe Comprehensive specalized hospital https://orcid.org/0000-0001-7141-5068

Musa Mohammed Ali

Hawassa University College of Medicine and Health Sciences

Research article

Keywords: Low birth weight, Determinants, Silte zone, Worabe, Ethiopia

Posted Date: April 12th, 2021

DOI: https://doi.org/10.21203/rs.3.rs-348265/v1

License: (c) (i) This work is licensed under a Creative Commons Attribution 4.0 International License.

Read Full License 


\section{Abstract}

Background: There is high incidence of neonatal death in Ethiopia. There are various factors that contribute to neonatal death. Low birth weight (LBW) contributes for about half of infant death. Identification of modifiable determinants of LBW for potential interventions has received little attention in southern parts of Ethiopia. The aim of this study was to identify determinants of LBW among mothers delivered at hospitals in Silte Zone, Southern Ethiopia.

Methods: A hospital-based unmatched case-control study was conducted in all public hospitals of Silte Zone. In the study, the number of mothers, cases and controls from each hospital was recruited using probability proportion to population size. Baby born with weight less than $2500 \mathrm{gm}$ were taken as a case where as a preceding three baby with birth weight of more than or equal to $2500 \mathrm{gm}$ was taken as control during study time in consecutive manner. Data was collected using pretested structured questionnaire, and by anthropometric measurements. Data was entered in to Epi Info 3.5.4 and exported to SPSS Version 20 software. Descriptive analysis and binary logistic regression model were used to calculate Odds ratio with $95 \%$ confidence intervals to estimate the association between the dependent and independent variables. Variables with a $p$-value less than 0.05 were considered as statistically significant.

Result: The mean \pm SD of birth weight of was $2174.47 \mathrm{gm} \pm 266.2$ for cases and $3370.48 \mathrm{gm} \pm 446.48 \mathrm{for}$ controls. After using multivariate logistic regression analysis, mothers who did not receive iron folate during pregnancy $[A O R=2.84(1.15,7.03)]$, mothers who had anemia (hemoglobin $<11 \mathrm{mg} / \mathrm{dl}$ ) during pregnancy $[A O R=1.03(1.12,6.24)]$, mothers who did not take additional meal [AOR $=3.25(1.64,6.44)]$, mothers who did not receive nutritional counseling during the current pregnancy [AOR $=6.93(4.80,11.76)]$, maternal under nutrition $[\mathrm{AOR}=3.62(2.64,6.47)]$, hypertensive disorder related to pregnancy $[\mathrm{AOR}=$ 2.76(1.34,5.71)] and inadequate Minimum Dietary Diversity Assessment(MDD-W) [AOR=6.65(2.31, 10.16)] were found as an independent and significant predictors of low birth weight.

Conclusions: Maternal under nutrition, mothers not receiving iron folate during pregnancy, mother who had anemia, lack of target nutritional counseling, mothers who did not receive additional food during pregnancy, hypertensive disorder related to pregnancy and inadequate MDD-W were significant determinants of LBW. The importance of nutritional counseling with iron folate supplements, adherence during pregnancy and maternal under nutrition screening needs to be strengthened effort to reduce incidence of LBW infants.

\section{Background}

The World Health Organization (WHO) defines as low birth weight (LBW) the weight of the newborn obtained within one hour after birth less than $2500 \mathrm{gm}$. Babies with LBW are 20 times more likely to die than heavier babies [1]. LBW is the most important predictor of infant growth and survival also noncommunicable diseases such as diabetes and cardiovascular disease later in life [2]. Infants born with 
LBW are characterized by high rates of morbidity and mortality due to infectious diseases, and are underweight, stunted or wasted in the start of the neonatal period and remain the same in their future life $[2,3]$. About $15-20 \%$ of all births worldwide are LBW, representing more than 20 million births a year. More than $95 \%$ of these are born in developing countries. More than $50 \%$ of LBW infants are born in 13 developing countries that have the highest incidence available ( $20 \%$ or higher), whereas only $14 \%$ are born in 53 countries with an incidence of less than $10 \%$,therefore, it is significant public health problem [4].

LBW is primarily due to babies born before 37 completed weeks of gestation (prematurity) and restricted fetal growth [2]. Studies indicate that preterm and intrauterine growth restrictions (IUGR) have strong relationship with LBW. The majority of LBW in developing countries including Ethiopia is due to IUGR which includes, poor maternal nutritional status at conception, chronic illness, chronic malaria, hypertension, inadequate dietary intake, short maternal stature due to the mother's childhood undernutrition and anemia whereas premature birth the most cause for LBW in developed countries $[2,5]$.

In low socio-economic settings, various determinant factors play a great role on affecting birth weight and infants future health. LBW is highly affected by factors like maternal diet from birth to pregnancy, maternal nutritional status, maternal medical condition, pregnancy induced complication and sociodemographic factors contribute to poor fetal growth [1, 3]. In the developing countries the magnitude of LBW could be underestimated due to high proportion of mothers give birth at home and newborns may not be registered as live birth and weighted (WHO, 2014). According to the 2005 Ethiopian demography and health survey (EDHS), $14 \%$ of babies were LBW and after five years the prevalence decreased by $3 \%$ and it was $11 \%$ and the based on respondents report the proportion of very small sized babies in Southern Nation Nationality and People Region (SNNPR) was $15.2 \%$ In SNNPR only $29 \%$ of women delivered at a health care facility $[6,7]$.

Multiple interventions involving monitoring progress of pregnancy, assessment of maternal nutritional status, iron and folic acid supplementation for pregnant mothers, maternal health and nutrition produce an average reduction in low birth weight incidence of $30 \%$ with greater effects on neonates [2-5]. Generally, preventive and control interventions for LBW morbidity and mortality should focus on: improved maternal nutritional status, prenatal care, micronutrient supplementation such as iron and folic acid, improved maternal health status and habits through treatment of complications, infections, health and nutrition education [2].

Hence, LBW is still a major public health problem-affecting infant, reducing their well-being and creating considerable demand for health service especially in developing countries. Therefore, the aim of this study was assess the determinant factors for LBW among newborns delivered at Silte zone, southern Ethiopia.

\section{Methods}




\section{Study setting and Period}

Silte zone is located $172 \mathrm{~km}$ south of Addis Ababa the capital of Ethiopia and $202 \mathrm{~km}$ from Hawassa capital of the south regional state. According to 2010E.C population projection, the zone consists of total population about 1,007,660 with male 498,792 (49.5\%) and female 508,868 (50.5\%) [7]. Based on health profile of Silte zone health department, the zone has one comprehensive and specialized hospital, 3 primary hospitals, 34 health center with 195 health posts which are governmental and 20 private medium clinics, 45 private primary clinics, 01 pharmacy and 41 drug stores which deliver routine preventive and curative health services to the community. All public hospitals in the zone that include one comprehensive and specialized and three primary governmental hospitals were included in this study.

\section{Study design and period}

A hospital-based unmatched case-control study was conducted from March to April 30, 2018.

\section{Source population}

For cases: source populations were all neonates delivered or mothers who delivered with birth weight < $2500 \mathrm{gm}$ in public hospitals of Silte zone.

For the controls: source populations were all neonates delivered or mothers who delivered with birth weight $\geq 2500 \mathrm{gm}$ in public hospitals of Silte zone.

\section{Study populations}

For cases the study populations were mothers who delivered babies with birth weight of less than $2500 \mathrm{gm}$ at the study sites. For the controls the study populations were mothers who delivered babies with birth weight of $\geq 2500 \mathrm{gm}$ during study period at the study sites.

\section{Eligibility criteria \\ Inclusion criteria}

For cases: babies who were born alive and birth weight of less than $2500 \mathrm{gm}$ were included in the current study.

For controls: babies who were born alive and birth weight of $\geq 2500 \mathrm{gm}$ were included in the study.

\section{Exclusion criteria}

For cases: neonates with birth weight of $\geq 2500 \mathrm{gm}$, mother lack hemoglobin and Professional Initiated Testing and Counseling (PITC) data on card, mothers in severe health problems and diabetic mother.

For controls: neonates with birth weight less than $2500 \mathrm{gm}$, mother lack hemoglobin and PITC data on card, mothers in severe health problems and diabetic mother.

\section{Sample size determination}


The sample size was determined using double proportion formula and calculated by Epi-Info version

3.5.4 statistical software package: with assumption of $95 \%$ confidence level $\left(\frac{Z \alpha}{2}=1.96\right)$, $80 \%$ of power ( $Z \beta=0.84)$, control to case ratio $3: 1(r=3)$, the odds ratio to be detected 2 and the $24.6 \%$ control group was exposed. After adding $5 \%$ potential non-response rate the final sample size was 404 (101 cases and 303 controls).

$$
\begin{aligned}
& \mathrm{n} 1=\left(\frac{Z \alpha}{2} \sqrt{\left(1+\frac{1}{\mathrm{r}}\right) \mathrm{p}(1-\mathrm{p})}+\mathrm{Z} \beta \sqrt{\left.p 1(1-p 1)+\frac{p 2(1-p 2)}{r}\right)}\right. \\
& (\mathrm{p} 1-\mathrm{p} 2)^{2} \\
& \text { Where: } \mathrm{P}=\frac{p 1+r p 2}{1+r} \mathrm{n} 2=\mathrm{n} 1 \times \mathrm{r}
\end{aligned}
$$

Note: Variables rural resident and birth interval 2 from Bale [8], MUAC taken from Kersa [9] and gestational age 37 weeks from Tigray [10].Sample size determination for predictors of LBW is presented

\begin{tabular}{|c|c|c|c|c|c|c|c|c|}
\hline \multirow[t]{2}{*}{ Variables } & \multirow{2}{*}{$\begin{array}{l}\text { Confidence } \\
\text { Level }\end{array}$} & \multirow[t]{2}{*}{ Power } & \multirow{2}{*}{$\begin{array}{l}\text { Ratio } \\
\text { (control } \\
\text { to } \\
\text { case) }\end{array}$} & \multirow{2}{*}{$\begin{array}{l}\text { Odds } \\
\text { Ratio } \\
\text { (OR) }\end{array}$} & \multirow{2}{*}{$\begin{array}{l}\text { Percent } \\
\text { of } \\
\text { controls } \\
\text { with } \\
\text { exposure }\end{array}$} & \multicolumn{2}{|c|}{ Sample size } & \multirow{2}{*}{$\begin{array}{l}\text { Total } \\
\text { sample } \\
\text { size }\end{array}$} \\
\hline & & & & & & Cases & Controls & \\
\hline $\begin{array}{l}\text { MUAC of } \\
\text { mother < } \\
23 \mathrm{~cm}\end{array}$ & 95 & 80 & 3 & 2 & 24.6 & 96 & 288 & 384 \\
\hline $\begin{array}{l}\text { Rural } \\
\text { Resident }\end{array}$ & 95 & 80 & 3 & 2 & 24.8 & 96 & 287 & 383 \\
\hline $\begin{array}{l}\text { Birth } \\
\text { interval } \leq 2 \\
\text { years }\end{array}$ & 95 & 80 & 3 & 2 & 25.3 & 95 & 285 & 380 \\
\hline $\begin{array}{l}\text { Gestational } \\
\text { age }<37 \\
\text { weeks }\end{array}$ & 95 & 80 & 3 & 2 & 28.6 & 92 & 274 & 366 \\
\hline
\end{tabular}
in Table 1.

Table 1 Sample size determination considering determinants associated with LBW

\section{Sampling technique}

All four public hospitals in the study area were included. The total number of mothers, cases and controls from each hospital was allocated by probability proportion to population size taking in to consideration of 2010 Ethiopian fiscal year one month, delivery performance $(220,191,160 \& 142$ for WCSH, Torra, Kibet and Alemgebeya Hospitals respectively) to total sample size of study. Then actual study 
participants were taken in respective consecutive single case, and preceding three normal birth babies as controls in each hospital until sample size gets its target during study period (Fig. 1).

\section{Data Collection}

The data was collected through interview using structured questionnaire adapted from related literatures $[8,9,11]$ and questionnaire was prepared in English and translated in to 'Amharic' language and back translated into English by independent persons to see consistency between the two versions by different language experts. It was used for collecting socio-demographic, maternal nutrition related factors, maternal health and reproductive health related factors. The questionnaire was pre-tested in Worabe town health center on $5 \%$ sample size before the actual data was collected to check for correctness and consistency of the questionnaire. Hemoglobin levels of each mother were taken from the card as hemoglobin and HIV test result was collected from mothers' card.

\section{Anthropometric measurement}

Standardization of anthropometric measurement was done by training the data collectors and comparing their measurement results with the results of the trainer, until the values of the data collectors and the trainer come to same measurement values. The weight of the newborns was measured within one hour upon delivery using a balanced Seca scale. The data collector measured mid-upper arm circumference (MUAC) of the mother two times and other data collector measured the same mother to see both intra and inter personal measuring differences, right after delivery using flexible non-stretchable standard tape measure in $\mathrm{cm}$. For left-handed women, the right arm was used instead. Height of mother was measured using digital machine. All measurements were taken twice and the average was taken.

\section{Minimum Dietary Diversity Assessment (MDD-W)}

MDD-W was collected using 24-hour recall method by MDD-W by use of the Global Dietary Diversity Indicator for Women [12].Briefly, the pregnant women were asked to recall the foods they had consumed in the previous 24 hour, probes to ascertain that no meal or snack was left out. A detailed list of all the ingredients of the dishes, snacks, or other foods consumed was generated to enable better classification of mixed dishes.

\section{Study variables}

\section{Dependent variable}

Low Birth Weight

\section{Independent variables}

Socio demographic factors: Maternal age, education, family income, occupation and place of residence Obstetric and maternal nutrition related factors: Minimum Maternal Dietary Diversity, Food Frequency, Maternal MUAC, maternal height, food taboos, prenatal care and diet counseling in current pregnancy, 
birth interval, parity, gestational age and iron-folate supplementation and high coffee consumption

Maternal medical conditions: Anemia, malaria, and hypertension

Infant related factors: Sex of neonate

\section{Operational Definitions}

Birth weight: is the weight of the newborn measured after one hour of birth.

Intrauterine growth restriction (IUGR): describe a fetus that has not reached its growth potential because of maternal nutritional or maternal medical condition related factor.

Low birth weight: neonate with birth weight less than 2,500 grams.

Minimum Dietary Diversity-Women: proportion of women who received foods from five or more food groups of the ten food groups [12]

Multiple births: a mother gives two or more babies the same time in the current pregnancy.

Normal Birth Weight: newborn with a weight measurement of above or equal to 2500 grams

Preterm birth: born alive before 37 completed weeks of pregnancy

Singleton birth: a mother gives a single baby in current pregnancy.

Term baby: a baby delivered after 37 completed weeks and before 42 weeks.

\section{Data quality control}

Structured instruments that prepared in English, translated in to an 'Amharic' and back translated into English by independent persons to see consistency between the two versions by different language experts. The instrument was pre-tested in Worabe town health center on $5 \%$ of sample size before the actual data being collected. All data collectors and supervisors who are BSC holder was trained for two days by the principal investigator before the data collection on the objectives of the study and how to interview, measure, fill the questionnaire and how handle questions asked by participants. The principal investigator and 4-selected supervisors closely supervised the data collection process. Standardization of anthropometric measurement was done by training the data collectors and comparing their measurement results with the results of the trainer. Weighting scales was checked two times per day by measuring an object with a known and constant weight for quality control purposes. The collected data was checked, cleaned for completeness and consistency on daily basis by investigator and supervisors.

\section{Data analysis and management}

Data was checked for completeness and consistencies and then edited, coded and entered by using EpiInfo version 5.3.4 and exported to SPSS version 20 and checked for missing values before analysis. 
Descriptive statistics was calculated for variables according to type. Frequency, means, medians and standard deviation was described for continuous variables after checking normality of data while the categorical variables was described by computing frequencies to determine the distribution of the variables in cases and controls. Bivariate and multivariable logistic regression analyses were computed to assess the association between study variables further to control all possible confounders. Then all variables significantly associated in bivariate analysis with $p$-value $\leq 0.25$ or candidates was further entered into multivariable logistic regression and then multivariable analysis was performed to see association between dependent and independent variables and to adjust for all possible declared confounders. To estimate strength of association adjusted odds ratio (AOR) with 95\% confidence interval was reported between study variables. A $p$-value less than 0.05 considered as statistically significant.

\section{Results}

\section{Socio demographic data}

Data were collected from 404 mothers and their respective neonates with a response rate of $100 \%$. The mean \pm SD of birth weight was $2174.47 \mathrm{gm} \pm 266$. 2 for cases and $3370.48 \mathrm{gm} \pm 446.48$ for controls. The majority of mothers among the cases (82.8\%) and the controls (80.9\%) were in the age group of 21-35 years followed by $<=20$ years age of mothers $29.7 \%$ among the cases and $13.9 \%$ among controls. Overall, most of the mothers in both cases (84.2\%) and control groups (51.5\%) were living in rural setting. More than half of $(64.4 \%)$ mothers of LBW babies had no formal education and this accounted for $27.1 \%$ among the mothers of normal birth weight (NBW) babies (Table 2). 
Table 2

Distribution of socio-demographic and economic characteristics among mothers of LBW cases and NBW controls in public hospitals of Silte zone, Southern Ethiopia, 2018 ( $\mathrm{N}=404: 101$ cases \& 303 controls).

\begin{tabular}{|c|c|c|c|c|}
\hline Variables & & Case (\%) & Control (\%) & $\begin{array}{l}\text { COR } \\
(95 \% \mathrm{Cl})\end{array}$ \\
\hline \multirow[t]{4}{*}{ Maternal age (year) } & $\leq 20$ & $30(29.7)$ & \multirow{2}{*}{$\begin{array}{l}42(13.9) \\
245(80.9)\end{array}$} & \multirow{2}{*}{$\begin{array}{l}0.18(0.04, \\
0.82)\end{array}$} \\
\hline & $21-35$ & $69(82.8)$ & & \\
\hline & \multirow[t]{2}{*}{$>35$} & $2(2)$ & \multirow{2}{*}{$16(5.3)$} & \multirow{2}{*}{$\begin{array}{l}0.44(0.10 \\
1.98)\end{array}$} \\
\hline & & & & \\
\hline \multirow[t]{2}{*}{ Infant sex } & Male & $21(20.8)$ & $222(73.3)$ & 1 \\
\hline & Female & $80(79.2)$ & $81(26.7)$ & $\begin{array}{l}0.96(0.6 \\
1.70)\end{array}$ \\
\hline \multirow[t]{2}{*}{ Residence } & Rural & $85(84.2)$ & $156(51.5)$ & $\begin{array}{l}0.2(0.11 \\
0.36)\end{array}$ \\
\hline & Urban & 16(15.8) & 147(48.5) & 1 \\
\hline \multirow[t]{3}{*}{ Educational status of mothers } & No formal education & $65(64.4)$ & $82(27.1)$ & $\begin{array}{l}1.62(1.45 \\
3.49)\end{array}$ \\
\hline & Primary education & $27(26.7)$ & $130(42.9)$ & \multirow{2}{*}{$\begin{array}{l}0.62(0.28 \\
1.39)\end{array}$} \\
\hline & $\begin{array}{l}\text { Secondary education } \\
\text { and more }\end{array}$ & $9(8.9)$ & $91(30.0)$ & \\
\hline \multirow[t]{4}{*}{ Occupation of mothers } & Employed & $8(7.9)$ & $39(12.9)$ & 1 \\
\hline & Housewife & $77(76.2)$ & 228(75.2) & $\begin{array}{l}0.54(0.12 \\
2.46)\end{array}$ \\
\hline & Merchant & $5(5.0)$ & $23(7.6)$ & $\begin{array}{l}1.06(0.31 \\
3.63)\end{array}$ \\
\hline & Others & 11(10.9) & $13(4.3)$ & $\begin{array}{l}0.64(0.24 \\
1.75)\end{array}$ \\
\hline \multirow[t]{3}{*}{$\begin{array}{l}\text { Average monthly family } \\
\text { income (ETB) }\end{array}$} & $<=1000$ & $44(43.6)$ & $66(21.8)$ & $\begin{array}{l}0.083(0.01, \\
0.65)\end{array}$ \\
\hline & $1001-5000$ & $56(55.4)$ & 219(72.3) & $\begin{array}{l}0.217 \\
(0.03,1.66)\end{array}$ \\
\hline & $>5000$ & $1(1.0)$ & $18(5.9)$ & 1 \\
\hline
\end{tabular}

LBW: Low birth weight, NBW: Normal birth weight, ETB: Ethiopian Birr, Cl: Confidence interval 
Proportions of antenatal care follow up among cases and controls were $98.0 \%$ and $100 \%$ respectively. Majority of mothers both in cases (59.4\%) and in controls (70.3\%) were gave to multiple births. Mothers who had birth space $<=24$ months was higher by $80.2 \%$ in cases and $46.9 \%$ in controls. Mothers with a height of less than $150 \mathrm{~cm}$ were higher than cases by $(11.9 \%)$ with controls $(1.0 \%)$. Under nutrition in mothers as defined by MUAC $<23 \mathrm{~cm}$ was $72.3 \%$ and $15.5 \%$ among cases and controls respectively. Mothers who had not received iron and folate were $51.5 \%$ among cases compared to $10.9 \%$ among controls. In addition, most of mothers $98.0 \%$ cases and $61.4 \%$ controls not had additional food intake during pregnancy. Almost all of mothers $100 \%$ among cases and $86.1 \%$ of mothers among controls had food frequency $<3$ meals a day. Mothers who had coffee $>4$ Ethiopian coffee cup per a day during pregnancy were $66.3 \%$ and $35.0 \%$ among cases and controls respectively. Moreover, mothers who had inadequate MDD-W were higher $89.1 \%$ among cases compared to $15.2 \%$ among controls. Maternal anemia (hemoglobin $<11 \mathrm{mg} / \mathrm{dl}$ ) among cases was $81.2 \%$ while it was $2.3 \%$ among controls (Table 3 ). 
Table 3

Distribution of obstetric and nutritional characteristics among mothers of LBW and NBW controls in hospitals of Silte zone, Southern Ethiopia, 2018 ( $\mathrm{N}=404: 101$ cases \& 303 controls).

\begin{tabular}{|c|c|c|c|c|}
\hline \multirow{2}{*}{$\begin{array}{l}\text { Variables } \\
\text { ANC follow up }\end{array}$} & \multirow[b]{2}{*}{ Yes } & \multicolumn{2}{|c|}{ Case (\%) Control (\%) } & \multirow{2}{*}{$\begin{array}{l}\text { COR }(95 \% \mathrm{Cl}) \\
1\end{array}$} \\
\hline & & $99(98.0)$ & $303(100)$ & \\
\hline & No & $2(2.0)$ & $0(0.0)$ & $3.61(1.27,10.28)$ \\
\hline \multirow[t]{2}{*}{ Parity (number of birth) } & Primigravida & $41(40.6)$ & $90(29.7)$ & $6.18(3.87,16.87)$ \\
\hline & Multipara & $60(59.4)$ & 213(70.3) & 1 \\
\hline \multirow[t]{2}{*}{ Birth Space /interval (month) } & $<=24$ & $81(80.2)$ & 142(46.9) & $2.18(1.27,5.73)$ \\
\hline & $>24$ & 20(19.8) & 161(53.1) & 1 \\
\hline \multirow[t]{2}{*}{ Height $(\mathrm{Cm})$} & $<150$ & 12(11.9) & $3(1.0)$ & $2.21(1.15,4.21)$ \\
\hline & $>=150$ & $89(88.1)$ & $300(99.0)$ & 1 \\
\hline \multirow[t]{2}{*}{ MUAC (cm) } & $<23$ & $73(72.3)$ & $47(15.5)$ & $4.17(2.99,7.88)$ \\
\hline & $>=23$ & 28(27.7) & $266(84.6)$ & 1 \\
\hline \multirow[t]{2}{*}{ Iron and folate supplementation } & Yes & $49(48.5)$ & 270(89.1) & 1 \\
\hline & No & $52(51.5)$ & $33(10.9)$ & $3.76(1.99,7.12)$ \\
\hline \multirow{3}{*}{$\begin{array}{l}\text { Number of iron and folate } \\
\text { supplementation (tablet) }\end{array}$} & $<30$ & 92(91.1) & $128(42.2)$ & $1.6(0.2,2.2)$ \\
\hline & $30-60$ & $6(5.9)$ & 107(35.3) & $3.25(1.9,7.9)$ \\
\hline & $>60$ & $3(3.0)$ & $68(22.4)$ & 1 \\
\hline \multirow{2}{*}{$\begin{array}{l}\text { Nutritional counseling during } \\
\text { pregnancy }\end{array}$} & Yes & $26(25.7)$ & 227(74.9) & 1 \\
\hline & No & $75(74.3)$ & $76(25.1)$ & $8.62(5.14,14.44)$ \\
\hline \multirow{2}{*}{$\begin{array}{l}\text { Additional food intake during } \\
\text { pregnancy }\end{array}$} & Yes & $2(2.0)$ & 117(38.6) & 1 \\
\hline & No & $99(98.0)$ & $186(61.4)$ & $4.47(2.63,7.61)$ \\
\hline \multirow[t]{2}{*}{ Food taboo } & Yes & $79(78.2)$ & 267(88.1) & $2.07(1.15,3.71)$ \\
\hline & No & $22(21.8)$ & $36(11.9)$ & 1 \\
\hline \multirow[t]{2}{*}{ Food frequency } & $<3$ & 101(100) & 261(86.1) & $1.07(1.32,5.17)$ \\
\hline & $>=3$ & $0(0.0)$ & $42(13.9)$ & 1 \\
\hline
\end{tabular}

LBW: Low birth weight, NBW: Normal birth weight, OR: Odds ratio, Cl: Confidence interval, MDD-W: Minimum Dietary Diversity Assessment, MUAC: Mid-Upper Arm Circumference, cm: centimeter, ANC: Antenatal care 


\begin{tabular}{|lllll|}
\hline Variables & \multicolumn{3}{l}{ Case (\%) Control (\%) } & COR (95\%Cl) \\
\hline Coffee intake & $<=2$ & $6(5.9)$ & $52(17.2)$ & 1 \\
& $3-4$ & $28(27.7)$ & $145(47.9)$ & $5.98(2.34,15.2)$ \\
\cline { 2 - 5 } & $>4$ & $67(66.3)$ & $106(35.0)$ & $2.83(1.74,5.45)$ \\
\hline MDD-W & Inadequate & $90(89.1)$ & $46(15.2)$ & $8.55(3.55,12.61)$ \\
\cline { 2 - 5 } & Adequate & $11(10.9)$ & $257(84.8)$ & 1 \\
\hline Hemoglobin level (mg/dl) & $<11$ & $82(81.2)$ & $7(2.3)$ & $2.6(2.54,7.13)$ \\
\cline { 2 - 5 } & $>=11$ & $19(18.8)$ & $296(97.7)$ & 1 \\
\hline Eating out of home & Yes & $97(96.0)$ & $162(53.5)$ & $1.47(2.5,4.13)$ \\
\cline { 2 - 5 } & No & $4(4.0)$ & $141(46.5)$ & 1 \\
\hline $\begin{array}{l}\text { LBW: Low birth weight, NBW: Normal birth weight, OR: Odds ratio, Cl: Confidence interval, MDD-W: } \\
\text { Minimum Dietary Diversity Assessment, MUAC: Mid-Upper Arm Circumference, cm: centimeter, ANC: } \\
\text { Antenatal care }\end{array}$ & & & \\
\hline
\end{tabular}

\section{Maternal Medical conditions}

In addition, few mothers in both cases and controls had history of malaria that was $10.9 \%$ and $2.3 \%$ respectively. Mothers who had history of anemia were $42.6 \%$ among cases compared to $8.3 \%$ among controls. Mothers who had history of hypertension were observed $14.9 \%$ among cases and $5.9 \%$ controls (Table 4).

Table 4

Distribution of maternal medical conditions among mothers of LBW cases and NBW controls in hospitals of Silte zone, Southern Ethiopia, 2018 (404: 101 cases \& 303 controls).

\begin{tabular}{|c|c|c|c|c|}
\hline \multicolumn{2}{|l|}{ Variables } & \multicolumn{2}{|c|}{ Case (\%) Control( \% ) } & \multirow{2}{*}{$\begin{array}{l}\text { COR }(95 \% \mathrm{Cl}) \\
5.17(1.95,13.72)\end{array}$} \\
\hline Malaria & Yes & 11(10.9) & $7(2.3)$ & \\
\hline & No & $90(89.1)$ & 296(97.7) & 1 \\
\hline \multirow[t]{2}{*}{ Anemia } & Yes & $43(42.6)$ & $25(8.3)$ & $8.24(4.67,14.55)$ \\
\hline & No & $58(57.4)$ & 278(91.7) & 1 \\
\hline \multirow[t]{2}{*}{ Hypertension } & Yes & $15(14.9)$ & $18(5.9)$ & $2.76(1.34,5.71)$ \\
\hline & No & $86(85.1)$ & $285(94.1)$ & 1 \\
\hline
\end{tabular}


In bivariate logistic regression analyses performed to identify candidate variables for multivariable logistic regression model in identifying determinants of low birth weight, all variables having p-value less than 0.25 were considered for the final multivariable logistic regression model (Table 5). 
Table 5

Bivariate analyses to identify candidate variables for multivariable logistic regression to identify determinants of LBW, Silte zone, Ethiopia, 2018 (404: 101 cases \& 303 controls).

\begin{tabular}{|c|c|c|c|c|c|}
\hline \multicolumn{2}{|l|}{ Factors } & \multicolumn{2}{|c|}{ Case (\%) Control (\%) } & \multirow{2}{*}{$\begin{array}{l}\text { Crude OR (95\%Cl) } \\
0.175(0.04,0.82)\end{array}$} & \multirow{2}{*}{$\begin{array}{l}p- \\
\text { value } \\
0.027\end{array}$} \\
\hline Maternal age (year) & $\leq 20$ & $30(29.7)$ & 42(13.9) & & \\
\hline & $21-35$ & $69(68.3)$ & $245(80.9)$ & $0.44(0.10,1.98)$ & 0.287 \\
\hline & $>35$ & $2(2.0)$ & $16(5.3)$ & 1 & \\
\hline \multirow[t]{2}{*}{ Residence } & Rural & $85(84.2)$ & $156(51.5)$ & $0.2(0.112,0.357)$ & \multirow[t]{2}{*}{0.000} \\
\hline & Urban & $16(15.8)$ & $147(48.5)$ & 1 & \\
\hline \multirow[t]{3}{*}{$\begin{array}{l}\text { Educational status of } \\
\text { mothers }\end{array}$} & $\begin{array}{l}\text { No formal } \\
\text { education }\end{array}$ & $65(64.4)$ & $82(27.1)$ & $1.62(1.45,3.49)$ & 0.000 \\
\hline & $\begin{array}{l}\text { Primary } \\
\text { education }\end{array}$ & $27(26.7)$ & $130(42.9)$ & $0.619(0.276,1.389)$ & 0.245 \\
\hline & $\begin{array}{l}\text { Secondary } \\
\text { education and } \\
\text { more }\end{array}$ & $9(8.9)$ & $91(30.0)$ & 1 & \\
\hline \multirow[t]{4}{*}{ Occupation of mothers } & Employed & $8(7.9)$ & $39(12.9)$ & 1 & \\
\hline & Merchant & $5(5.0)$ & $23(7.6)$ & $0.54(0.12,2.46)$ & 0.429 \\
\hline & Housewife & 77(76.2) & $228(75.2)$ & $1.06(0.31,3.63)$ & 0.926 \\
\hline & Others & 11(10.9) & $13(4.3)$ & $0.64(0.24,1.75)$ & 0.388 \\
\hline \multirow{3}{*}{$\begin{array}{l}\text { Average monthly } \\
\text { family Income }\end{array}$} & $<=1000$ & $44(43.6)$ & $66(21.8)$ & $0.083(0.01,0.65)$ & 0.017 \\
\hline & $1001-5000$ & $56(55.4)$ & $219(72.3)$ & $0.217(0.03,1.66)$ & 0.141 \\
\hline & $>5000$ & $1(1.0)$ & $18(5.9)$ & 1 & \\
\hline \multirow[t]{2}{*}{ Height $(\mathrm{Cm})$} & $<150$ & 12(11.9) & $3(1.0)$ & $2.21(1.15,4.21)$ & 0.000 \\
\hline & $>=150$ & $89(88.1)$ & $300(99.0)$ & 1 & \\
\hline \multirow[t]{2}{*}{ MUAC } & $<23$ & $73(72.3)$ & $47(15.5)$ & $4.17(2.99,7.88)$ & 0.000 \\
\hline & $>=23$ & $28(27.7)$ & $266(84.6)$ & 1 & \\
\hline \multirow[t]{2}{*}{ Infant sex } & Male & $21(20.8)$ & $222(73.3)$ & 1 & \\
\hline & Female & $80(79.2)$ & $81(26.7)$ & $0.96(0.6,1.70)$ & 0.000 \\
\hline
\end{tabular}

LBW: Low birth weight, OR: Odds ratio, Cl: Confidence interval, MDD-W: Minimum Dietary Diversity Assessment, MUAC: Mid-Upper Arm Circumference, cm: centimeter, ANC: Antenatal care 


\begin{tabular}{|c|c|c|c|c|c|}
\hline \multicolumn{2}{|l|}{ Factors } & \multicolumn{2}{|c|}{ Case (\%) Control (\%) } & \multirow{2}{*}{$\begin{array}{l}\text { Crude OR }(95 \% \mathrm{Cl}) \\
1\end{array}$} & \multirow{2}{*}{$\begin{array}{l}\begin{array}{l}p- \\
\text { value }\end{array} \\
0.000\end{array}$} \\
\hline Iron and folate & Yes & $49(48.5)$ & $270(89.1)$ & & \\
\hline & No & $52(51.5)$ & $33(10.9)$ & $3.76(1.99,7.12)$ & \\
\hline \multirow[t]{2}{*}{ Anemia } & Yes & $43(42.6)$ & $25(8.3)$ & $8.24(4.67,14.55)$ & 0.00 \\
\hline & No & $58(57.4)$ & 278(91.7) & 1 & \\
\hline \multirow[t]{2}{*}{ ANC follow up } & Yes & 99(98.0) & $303(100)$ & 1 & 0.999 \\
\hline & No & $2(2.0)$ & $0(0.0)$ & $3.61(1.27,10.28)$ & \\
\hline \multirow[t]{2}{*}{ Birth space } & $<24$ & $81(80.2)$ & $142(46.9)$ & $2.18(1.27,5.73)$ & 0.000 \\
\hline & $>=24$ & $20(19.8)$ & $161(53.1)$ & 1 & \\
\hline \multirow[t]{2}{*}{ Parity } & Primigravida & $41(40.6)$ & $90(29.7)$ & $6.18(3.87,16.87)$ & 0.044 \\
\hline & Multipara & $60(59.4)$ & 213(70.3) & 1 & \\
\hline \multirow[t]{2}{*}{ Nutritional counseling } & Yes & $26(25.7)$ & $227(74.9)$ & 1 & 0.000 \\
\hline & No & $75(74.3)$ & $76(25.1)$ & $8.62(5.14,14.44)$ & \\
\hline \multirow[t]{2}{*}{ Food taboo } & Yes & $79(78.2)$ & 267(88.1) & $2.07(1.15,3.71)$ & 0.015 \\
\hline & No & $22(21.8)$ & $36(11.9)$ & 1 & \\
\hline \multirow{2}{*}{$\begin{array}{l}\text { Habits diet out of } \\
\text { home }\end{array}$} & Yes & $97(96.0)$ & $162(53.5)$ & $1.47(2.5,4.13)$ & 0.000 \\
\hline & No & $4(4.0)$ & $141(46.5)$ & 1 & \\
\hline \multirow[t]{2}{*}{ Food frequency } & $<3$ & 101(100) & $261(86.1)$ & $1.07(1.32,5.17)$ & 0.997 \\
\hline & $>=3$ & $0(0.0)$ & $42(13.9)$ & 1 & \\
\hline \multirow[t]{3}{*}{ Coffee intake } & $<=2$ & $6(5.9)$ & $52(17.2)$ & 1 & 0.281 \\
\hline & $3-4$ & $28(27.7)$ & $145(47.9)$ & $5.98(2.34,15.24)$ & 0.000 \\
\hline & $>4$ & 67(66.3) & $106(35.0)$ & $2.83(1.74,5.45)$ & \\
\hline \multirow{2}{*}{$\begin{array}{l}\text { Additional food intake } \\
\text { during pregnancy }\end{array}$} & Yes & $2(2.0)$ & 117(38.6) & 1 & 0.000 \\
\hline & No & $99(98.0)$ & $186(61.4)$ & $4.47(2.63,7.61)$ & \\
\hline \multirow[t]{2}{*}{ MDD-W } & Inadequate & $90(89.1)$ & $46(15.2)$ & $8.55(3.55,12.61)$ & 0.000 \\
\hline & Adequate & 11(10.9) & $257(84.8)$ & 1 & \\
\hline
\end{tabular}

LBW: Low birth weight, OR: Odds ratio, Cl: Confidence interval, MDD-W: Minimum Dietary Diversity Assessment, MUAC: Mid-Upper Arm Circumference, cm: centimeter, ANC: Antenatal care 


\begin{tabular}{|c|c|c|c|c|c|}
\hline \multicolumn{2}{|l|}{ Factors } & \multicolumn{2}{|c|}{ Case (\%) Control (\%) } & \multirow{2}{*}{$\begin{array}{l}\text { Crude OR }(95 \% \mathrm{Cl}) \\
2.6(2.54,7.13)\end{array}$} & \multirow{2}{*}{$\begin{array}{l}p \text { - } \\
\text { value }\end{array}$} \\
\hline Hemoglobin level & $<11$ & $82(81.2)$ & $7(2.3)$ & & \\
\hline & $>=11$ & 19(18.8) & 296(97.7) & 1 & \\
\hline \multirow[t]{2}{*}{ Malaria } & Yes & 11(10.9) & $7(2.3)$ & $5.168(1.95,13.72)$ & 0.001 \\
\hline & No & $90(89.1)$ & 296(97.7) & 1 & \\
\hline \multirow[t]{2}{*}{ Hypertension } & Yes & $15(14.9)$ & $18(5.9)$ & $2.762(1.336,5.710)$ & 0.006 \\
\hline & No & 86(85.1) & $285(94.1)$ & 1 & \\
\hline
\end{tabular}

\section{Multivariate logistic regression}

The selected independent covariates with $p$-value $<0.25$ in bivariate logistic regression were entered into the multivariable logistic regression model to isolate the independent predictors of LBW using backward elimination stepwise likelihood ratio method. To control potential confounders such age, residence, educational status, maternal height, birth space, food taboo, coffee intake and malaria multivariate logistic regression was done statistical significant association was observed between nutritional counseling, iron and folate supplementation, anemia (hemoglobin $<11 \mathrm{mg} / \mathrm{dl}$ ), additional meals per day, women dietary diversity, maternal MUAC and hypertensive disorder of pregnancy. The result of the analysis showed that mothers who deliver female sex less likely 0.5 times to low birth baby than male $(\mathrm{AOR}=0.44(0.11,0.75))$. Mothers who did not take iron and folate supplementation were more likely to 2.8 times deliver low birth weight babies than mothers who did take iron and folate supplementation during pregnancy $(A O R=2.84(1.2,7.0)$ ). In addition, anemic mothers (hemoglobin $<11 \mathrm{mg} / \mathrm{dl})$ were more likely to 1.03 times deliver low birth weight babies than mothers who had hemoglobin level of $>=$ $11 \mathrm{mg} / \mathrm{dl}$ during pregnancy $(A O R=1.03(1.12,6.24))$. Mothers who did not receive nutritional counseling during the current pregnancy were 6.9 times more likely to have low birth weight neonate $(A O R=$ $6.93(4.80,11.76))$ than mother who did receive nutritional counseling. Similarly, mothers who did not take additional meal during the current pregnancy were more likely to have 3.3 times a neonate with low birth weight compared to those mothers who had additional meal during pregnancy $(A O R=3.25(1.64,6.44)$ ). The odds of LBW among undernourished mothers 3.6 times higher as compared to their well-nourished counterparts was $(A O R=3.62(2.64,6.47))$. Also, mothers who had history of hypertension nearly three times odds of giving LBW neonates compared to non-hypertensive mothers (AOR $=2.76(1.34,5.71)$ ). Furthermore, the odds of LBW babies among mothers with inadequate MDD-W were 6.65 times higher than mothers with adequate MDD-W $(A O R=6.65(2.31,10.16))$. Details of multivariate analysis were presented below (Table 6). 
Table 6

Determinants of LBW in multivariable logistic regression analysis for newborns delivered in hospitals of Silte zone, Southern Ethiopia, 2018 (404: 101 cases \& 303 controls).

\begin{tabular}{|c|c|c|c|c|c|}
\hline Factors & \multicolumn{2}{|c|}{ Case (\%) Control (\%) } & Crude OR [95\% Cl] & Adjusted OR [95\% Cl] & $p$-value \\
\hline \multicolumn{6}{|c|}{ Sex of newborn } \\
\hline Male & 21(20.8) & $222(73.3)$ & 1 & 1 & \\
\hline Female & $80(79.2)$ & $81(26.7)$ & $0.96(0.6,1.70)$ & $0.44(0.11,0.75)$ & 0.000 \\
\hline \multicolumn{6}{|c|}{ Iron and folate supplementation } \\
\hline Yes & $49(48.5)$ & $270(89.1)$ & 1 & 1 & \\
\hline No & $52(51.5)$ & $33(10.9)$ & $3.76(1.99,7.12)$ & $2.84(1.15,7.03$ & 0.023 \\
\hline \multicolumn{6}{|c|}{ Hemoglobin level } \\
\hline$<11$ & $82(81.2)$ & $7(2.3)$ & $2.56(2.54,7.13)$ & $1.03(1.12,6.24)$ & 0.000 \\
\hline$>=11$ & 19(18.8) & 296(97.7) & 1 & 1 & \\
\hline \multicolumn{6}{|l|}{ MDD-W } \\
\hline Inadequate & $90(89.1)$ & $46(15.2)$ & $8.55(3.55,12.61)$ & $6.65(2.31,10.16)$ & 0.017 \\
\hline Adequate & 11(10.9) & $257(84.8)$ & 1 & 1 & \\
\hline
\end{tabular}

\section{Discussion}

This study revealed that nutritional counseling, hypertensive disorder related to pregnancy, anemia and additional meal frequency per a day, iron and folate supplement, inadequate minimum dietary diversity and maternal under nutrition during pregnancy as significant predictors of LBW.

Mothers who did not receive nutritional counseling during current pregnancy had 6.9 odds for giving LBW compared to mothers who did receive nutritional counseling. This might be due to the fact that nutritional counseling might improve their feeding behavior and hence, their nutritional status too which might in turn could help the mothers to decrease the risk of delivering LBW baby. This finding was consistent with other study conducted in Gondar University Hospital where mothers who didn't have ANC follow up had higher odds of giving LBW babies while this finding was attributed to the routine provisions of nutritional counseling during ANC visits [13].

The risk of low birth weight was 3.3 times among mothers who did not receive additional food during current pregnancy as compared to mothers who did receive additional food during current pregnancy. These findings were consistent with other similar studies conducted in Jimma, Ethiopia and Ghana [14, 15]. Mothers who consumed more food during pregnancy were $88 \%$ less likely to give birth to a low birth weight infant than those who ate the same as before pregnancy [15]. Mothers who did not take iron and folate supplementation were nearly 3 times at risk to deliver babies with LBW than mothers who did take 
iron and folate supplementation during pregnancy. This finding is in agreement with a study conducted in Bangladesh that showed intake of iron and folate supplements during pregnancy was found to have a protective effect against LBW [16]. These findings were also consistent with other similar studies done in rural parts of Oromia, Ethiopia, Pakistan and a study from developed country [14, 15, 17]. Iron folate supplementation during pregnancy elevates hemoglobin level and prevents women from becoming anemic and consecutive increased risk of giving LBW babies because the required amounts may not be supplied from dietary intake during this period [16]. Furthermore, an overview of controlled trials suggested a $41 \%$ reduction in the prevalence of intrauterine growth retardation with folic acid supplementation, suggesting folate added to antenatal iron could independently affect birth weight of newborns [18].

Moreover, the current study showed that mothers with low level of hemoglobin were 1.03 times at risk to deliver LBW babies compared to mothers who had normal hemoglobin. This finding is consistent with other studies $[16,19,20]$. Mothers who did not receive iron folate and with low level of hemoglobin during pregnancy was more prone to give birth to LBW babies in Yemen [19]. It was also reported that maternal low hemoglobin level had a negative effect on birth weight among neonates in Bangladesh [16]. This might also be because of that micronutrient deficiencies during pregnancy had been shown to have serious implications on the developing fetus and hence, birth size [21]. Low level of hemoglobin could impair oxygen delivery to the fetus and thus interfere with normal intrauterine growth [22].

Inadequate women dietary diversity and maternal under nutrition during pregnancy independently and significantly affected LBW in our study. The consequences of inadequate nutritional intake and poor nutritional status for women during pregnancy not only directly affects women's health status, but may also have a negative impact on birth weight and early development. Mothers having inadequate MDD-W had 6.65 times odds of giving birth to LBW babies. This finding was consistent with a study done in rural Oromia region in Ethiopia, in which women in the inadequate MDD-W group had an increased risk of LBW and preterm baby compared with women in the adequate MDD-W group [14]. Similarly, a study from Ghana shows that Women dietary diversity score and dietary patterns were found to be protective against low birth weight [15]. However, a recent randomized controlled trial in India reported that an intervention that increased consumption of dairy, fruits, and green leafy vegetables before and during pregnancy through a specially formulated snack had no effect on birth weight [23]. This discrepancy might be due to differences in study population, geographical location, and the study design.

Similarly, maternal under nutrition as measured by maternal MUAC of less than $23 \mathrm{~cm}$ significantly increased 3.6 times the odds of having LBW babies in the present study. This finding is in agreement with an observational cohort study conducted on 1295 live birth and pregnant women to measure the incidence and determinants of LBW in a rural population in Kersa district, Western Ethiopia, where maternal MUAC of less than $23 \mathrm{~cm}$ was found to significantly predict LBW in this cohort [9]. Moreover, recent study from Yemen showed that maternal under-nutrition defined by MUAC of less than $23 \mathrm{~cm}$ was significantly correlated to LBW [19]. The observed findings might be because of the fact that anthropometric measurements directly or indirectly measures nutritional status. Even though either acute 
or chronic maternal malnutrition has direct effect on the birth weight of a baby, acute maternal malnutrition has more pronounced effect [9].

Mother who had hypertensive disorder related to pregnancy was 2.8 times at risk for low birth weight in the present study. This finding is consistence with a case control study conducted in Malaysia showed that hypertensive mother had significant association with LBW infants [24]. This study agreement with another case control study done in India also showed that women with pregnancy-induced hypertension have 2.5 times more risk of giving birth to LBW babies [25].

\section{limitation of the study}

There might be chances of recall bias as respondents had to remember past history like dietary diversity, food frequency, number of ANC visit, number of iron folate tablet taken.

\section{Conclusion}

Lack of nutritional counseling during pregnancy at ANC visit, lack of iron folate supplementation, female sex, low level of hemoglobin, lack of additional food intake during pregnancy, MUAC less than $23 \mathrm{~cm}$, hypertension during pregnancy and inadequate MDD-W were identified as significant predictors of LBW among neonates under the study.

\section{Abbreviations}

ANC: Antenatal Care, IUGR: Intra-Uterine Growth Restriction, LBW: Low Birth Weight, MUAC: Mid-Upper Arm Circumference, UNICEF: United Nations International Children's Fund, UNSCN: United Nations System Standing Committee on Nutrition, WCSH: Worabe Comprehensive Specialized Hospital, WHO: World Health Organization.

\section{Declarations}

\section{Consent for publication}

Not applicable.

\section{Availability of data and materials}

All necessary data are available within the paper.

\section{Ethical approval and consent to participant}

The study was approved by the Institutional Review Board of Wolaita Sodo University, College of health sciences and medicine. Permission letter was obtained from the all study site. The objectives, expected outcomes, benefits, and risks of the study were explained for study patricians. Data was collected after 
written informed consent was obtained. The study was conducted in accordance with the Declaration of Helsinki.

\section{Authors' contributions}

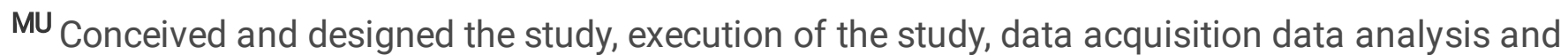
interpretation, article preparation. ${ }^{\text {AW\&MMA }}$ Data analysis, interpretation and prepared initial draft of the manuscript for publication. The final manuscript was read and approved by all authors. All authors reviewed and agreed on the final version of the article before submission.

\section{Acknowledgment}

We would like to thank all of public hospital for facilitating the study. We also acknowledge all study participants for their willingness to take part in the study.

\section{Funding}

No funding was allocated for this study.

\section{Competing Interests}

The authors declare no competing interest.

\section{References}

1. UNICEF, W., Low Birth Weight: country, regional and global estimate. New York: UNICEF and WHO, 2014

2. UNICEF, W., strategies to promote optimal fetal growth and minimize the prevalence of LBW in Sri lanka: .Healt Sector Response, Family Health Bureau MOH, WHO, 2013.

3. UNICEFb, Improving Child Nutrition Report. www.unicef.org/publications/index.htm, 2013.

4. WHO, WHA Global Nutrition Targets 2025: Low Birth Weight Policy Brief. Nutrition: low birth weight 2014

5. WHO, guide line on optimal feeding of low birth weight in low and middle income countries. Geneva, World Health Organization. http://www.who.int/about/licensing/copyright_form/en/index.html, 2011

6. EDHS (Ethiopian Demographic and Health Survey) 2011. Ethiopian Central Statistical Agency and ICF International, 2012.

7. CSA Federal Democratic Republic of Ethiopia Central Statistical Agency, Population Projection of Ethiopia for All Regions at Wereda Level from 2014 - 2017, Addis Ababa 2013.

8. Demelash.et. al, Risk factors for low birth weight in Bale Zone Hospital, South East Ethiopia, a case control study BMC Pregnancy and Childbirth, 2015. 15: p. 264. 
9. Assefa N, B.Y., Worku A, Wealth Status, Mid Upper Arm Circumference and Antenatal Care are determinants for low birth weight in Kersa, Ethiopia. PLOS One, 2012. 7(6).

10. Gebremedhin. et.al, Maternal associated factors of low birth weight: a hospital based cross-sectional mixed study in Tigray, Northern Ethiopia. BMC Pregnancy and Childbirth 2015. 15: p. 222.

11. Ethiopian Demographic and Health Survey (EDHS) 2011. Ethiopian Central Statistical Agency and ICF International, 2012.

12. Food and Agriculture Organization: A Minimum Dietary Diversity for Women. A guide for measurement: FANTA 2016.

13. Adane AA, Ayele TA, Ararsa LG, Bitew BD, Zeleke BM. Adverse birth out comes among deliveries at Gondar University Hospital, Northwest Ethiopia. BMC pregnancy and childbirth. 2014;14:90.

14. ZerfuTA ,Umeta M and Baye K. Dietary diversity during pregnancy is associated with reduced risk of maternal anemia, preterm delivery, and low birth weight in a prospective cohort study in rural Ethiopia. Am J Clin Nutr,2015,115.116798.

15. Michael OF, Louis M, Nsowah-Nuamah NN. Low Birth Weight and Associated Maternal Factors in Ghana. J Biol, Agr Healthcare, 2013; 3(7):205- 11.

16. Abel Gebreet. al, Assessment of Factors Associated with Adherence to Iron-Folic Acid Supplementation Among Urban and Rural Pregnant Women in North Western Zone of Tigray, Ethiopia: Comparative Study International Journal of Nutrition and Food Sciences, 2015. 4(2): p. 161168

17. Khan A, Nasrullah FD, Jaleel R. Frequency and risk factors of low birth weight in term pregnancy. Pakistan journal of medical sciences. 2016 Jan;32(1):138.

18. Christian P.,et.al. Effects of maternal micronutrient supplementation on fetal loss and infant mortality: a cluster-randomized trial in Nepal: Am J ClinNutr December 2003 vol. 78 no. 6 1194-1202.

19. Muftah S. Maternal under-nutrition and anemia factors associated with low birth weight babies in Yemen. Int J Community Med Public Health, 2016;3:2749-56.

20. Dubey D.K., a.N.D.C., An Epidemiological Model Investigating the association between mothers nutritional status and low birth weight in India. http://dx.doi.org/10.4236/health.2016.83027 2016. 8: p. 251-261.

21. Abdullahiet. al., Antenatal iron and folic acid supplementation use by pregnant women in Khartoum, Sudan. BMC Research Notes 2014. 7: p. 498.

22. Muchemi OM, Echoka E, Makokh A. Factors associated with low birth weight among neonates born at Olkalou District Hospital, Central Region, Kenya. Pan Afr Med J. 2015; 20:108.

23. Potdar RD, et al. Improving women's diet quality preconceptionally and during gestation: effects on birth weight and prevalence of low birth weight-a randomized controlled efficacy trial in India (Mumbai Maternal Nutrition Project). Am J ClinNutr 2014; 100:1257-68?

24. Sutan, R., Mohtar, M., Mahat, A.N. and Tamil, A.M, Determinants of low birth weight Infants: $A$ matched case control study. Open Journal of Preventive Medicine, 2014. 4: p. 91-99. 
25. Ghimire R., P.D.B., Phalke V.D., Banjade B., Singh AK. , Determinants of low birth weight: Acase control Study in Pravara Rural Hospital in Western Maharashtra, India. International Journal of Scientific Research, 2014. 3(7).

\section{Figures}

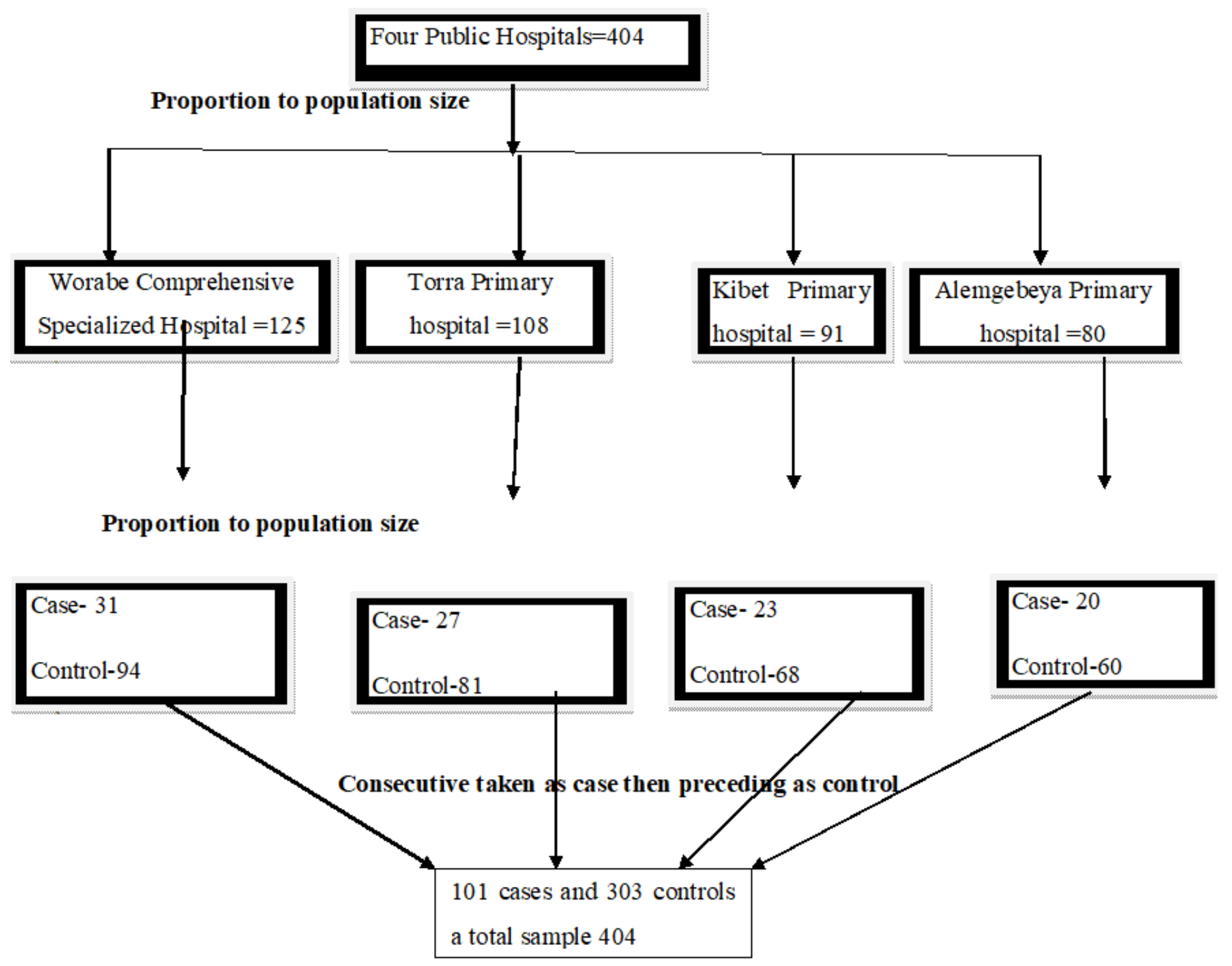

Figure 1

Schematic presentation of the sampling procedure in the study area 